\title{
Bilateral desmoid tumor of the breast: case series and literature review
}

\section{Phanchaporn \\ Wongmaneerung}

Areewan Somwangprasert

Kirati Watcharachan

Chagkrit Ditsatham

Department of Surgery, Faculty of Medicine, Chiang Mai University, Chiang Mai, Thailand
Correspondence: Areewan

Somwangprasert; Kirati Watcharachan

Department of Surgery, Faculty of

Medicine, Chiang Mai University, II 0

Suthep Road, Maung, Chiang Mai 50200

Thailand

Tel +6653935533

Email asomwang@yahoo.com; kvatchara@ yahoo.com
This article was published in the following Dove Press journal:

International Medical Case Reports Journal

22 August 2016

Number of times this article has been viewed

Background: Desmoid tumor of the breast is very rare and locally aggressive but has no distant metastasis. Bilateral lesions are extremely rare, found in only $4 \%$ of patients. Two cases of bilateral desmoid tumor of the breast are reported. The clinical presentation, diagnosis, imaging, treatment, and follow-up outcomes of recurrence as well as a brief literature review are provided. Case reports: Case 1 is a 31-year-old woman who presented with nipple retraction. An ultrasound revealed BIRAD V in both breasts. She underwent a bilateral excisional biopsy under ultrasound mark with the pathology result of extra-abdominal desmoid tumor in both breasts. The patient had a bilateral mastectomy with silicone implantation due to the involved margins by excision. She remained tumor free after 7-year follow-up. Case 2 is a 28-year-old woman who presented with a lump on her right breast that she had discovered $\sim 2$ months earlier. An ultrasound showed a spiculated mass in the right breast and some circumscribed hypoechoic masses in both breasts. A bilateral breast excision was done. The pathology result was an extraabdominal desmoid tumor. She had recurrence on both sides and underwent a mastectomy and silicone implantation. The tumor has not recurred after 1-year follow-up.

Conclusion: Imaging cannot distinguish between benign breast lesions and malignancy. Pathology results are helpful in making a definitive diagnosis. Given that the desmoid tumor is locally aggressive, a local excision with clear margins is recommended. Chemotherapy and hormonal treatment are controversial.

Keywords: extraabdominal desmoid tumor, rare breast disease, breast fibromatosis

\section{Introduction}

Desmoid tumor or fibromatosis of the breast is a benign, slow-growing fibroblastic neoplasm. It is characterized by being locally aggressive with frequent recurrence without metastasis. ${ }^{1-3}$ Its pathology is characterized by nonencapsulated, proliferation of well-differentiated spindle cells. Fibromatosis of the breast can occur either sporadically or genetically, for example, familial adenomatous polyposis (FAP) and Gardner's syndrome (GS)., ${ }^{4,5}$ Desmoid tumor is a very rare lesion accounting for only $0.2 \%$ of breast tumors. Although usually unilateral and solitary tumors are common in patients, bilateral desmoid tumors have been reported in up to $4 \%$ of patients, ${ }^{1}$ and multicentric lesions have also been found. ${ }^{6} \mathrm{~A}$ common presentation is a palpable mass that is sometimes associated with skin retraction or fixation to the underlying pectoralis major muscle. Only eight cases of bilateral breast fibromatosis have been reported in the literature. ${ }^{1,7-10}$ In this article, we report two cases of bilateral desmoid tumor of the breast, which is very rare. The patients were informed that the case will be 
published, and both agreed to this. Written informed consent was not obtained because the ethics committee at Chiang Mai University does not require patient consent for case reports which do not identify the patients.

\section{Case presentation Case I}

A 31-year-old woman came to the Chiangmai University Hospital having felt a lump in her right breast for $\sim 2$ months prior to her presentation. She had no nipple discharge, no nipple retraction, or no skin changes. She did not have any medical history. There was no family history of breast cancer, ovarian cancer, FAP, or GS. She had not taken oral contraceptives, and there was no history of trauma or previous surgery of the breast or chest wall.

On physical examination, breast mass or any breast abnormality could not be identified. A bilateral breast ultrasound showed no abnormal breast lesions. She was advised to conduct breast self-examinations.

Four months later, she returned with right nipple retraction, but no nipple discharge or other palpable breast mass. This time, a bilateral breast ultrasound showed an ill-defined spiculated border hypoechoic lesion $(13.6 \times 7.4 \times 12.4 \mathrm{~mm})$ in the left breast and a subareolar hypoechoic solid lesion $(13.6 \times 7.4 \times 12.4 \mathrm{~mm})$ in the right breast without internal microcalcification categorized as BIRAD V. An additional mammogram showed a hyperdense breast (Figure 1).

The cytology from fine needle aspiration under ultrasound guide yielded unsatisfactory specimens from both sides; therefore, an excisional biopsy was conducted on both breasts under ultrasound marks on the skin. An intraoperative review found an infiltrating, nonencapsulated mass at both sites.

The pathology results of both lesions included some bland-looking spindle cells in collagenous stroma. Immunohistochemical studies showed positive vimentin and actin with negative desmin and CD34 that was compatible with extra-

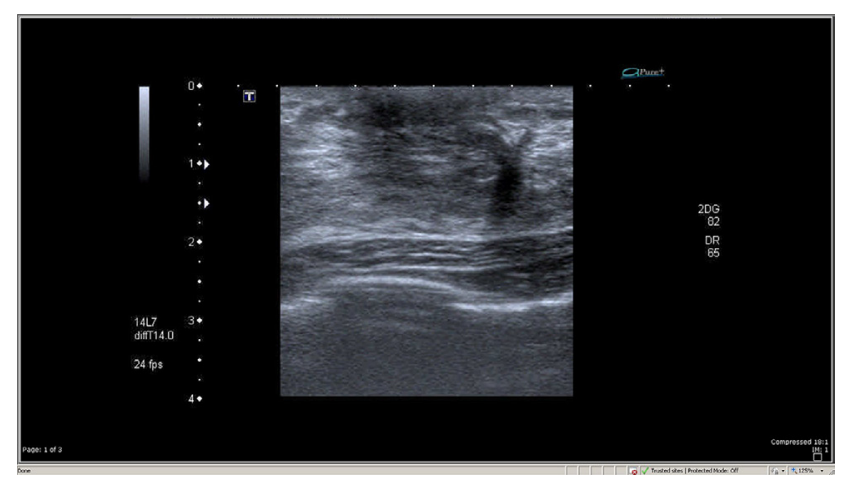

Figure I A hypoechoic solid mass with ill-defined border with no microcalcification. abdominal desmoid tumor. Free surgical margins were noted on the right side but focally approached the margins on the left side. Since this tumor is locally aggressive, the patient was advised to choose between a widened excision or a mastectomy to reduce the recurrence rate. She selected a bilateral mastectomy with silicone implantation. Her breasts were examined every 6 months at the clinic for the recurrence of the desmoid tumor for the first 5 years and then annually thereafter. At the time of this report, she has been disease-free for 7 years.

\section{Case 2}

A 28-year-old woman presented with a palpable right breast mass and breast pain that started 2 months before she presented to the hospital. There was no family history of breast cancer, ovarian cancer, FAP, or GS. She had no other illness and no history of oral contraceptive use. There was no previous breast surgery or trauma to the breast or chest wall. Her physical examination revealed a well-defined mass at 6 o'clock on the right breast, which was of firm consistency, movable, and not tender.

A breast ultrasound showed two partially spiculated border hypoechoic masses at R9 $(11 \times 7 \times 22 \mathrm{~mm})$ and R12 $(6 \times 4 \times 7 \mathrm{~mm})$ and four circumscribed hypoechoic nodulelooking benign lesions at R7 $(16 \times 11 \times 16 \mathrm{~mm}$, corresponding to the palpable lump), R10 $(8 \times 5 \times 9 \mathrm{~mm}), \mathrm{L} 2(6 \times 4 \times 6 \mathrm{~mm})$, and L4 $(7 \times 3 \times 7 \mathrm{~mm})$.

Fine needle aspiration was done under ultrasound guide at R9 and R12 (the spiculated masses); the result of R9 was an unsatisfactory specimen, and the result of R12 was clear fluid. A bilateral excisional biopsy was conducted using an ultrasound marker.

The pathology result from the right breast revealed an irregular lesion consisting predominantly of dense fibrous stroma, with some benign spindle cells $(1.7 \times 0.5 \mathrm{~mm})$ with focally approached margins. Immunohistochemical studies showed positive vimentin and actin with negative desmin and CD34 that was compatible with an extra-abdominal desmoid tumor. Another part of the breast indicated fibrocystic changes and fibroadenoma. The left breast pathology showed fibrocystic changes with an increased amount of fibrous stroma.

At the patient's 6-months follow-up, she had developed new irregular hypoechoic masses in her right breast $\mathrm{R} 8$ $(18 \times 2 \mathrm{~mm})$ and $\mathrm{R} 1(0.8 \times 11 \mathrm{~mm}$; previously reported as $\mathrm{R} 12: 6 \times 7 \mathrm{~mm}$ ), which were suspected to be recurrent extraabdominal desmoid tumors. A right subcutaneous mastectomy was scheduled, and the pathology result showed spindle cells among dense collagenous stroma that was compatible with a desmoid tumor $(1.7 \mathrm{~cm})$. 
Six months later, she developed a new mass in her left breast. The ultrasound showed an irregular hypoechoic mass at L11 medial to the surgical scar of $6.5 \mathrm{~mm}$. This was suspected to be a recurrent fibrous (desmoid) tumor. A left subcutaneous mastectomy with silicon implantation was scheduled. The pathology result was dense fibrous stroma with some spindle cells that were compatible with extra-abdominal desmoid tumor at the previous resected area. With free margin, the immunohistochemical studies showed positive vimentin and actin with negative desmin and CD34 (Figures 2-4). The patient was followed up every 6 months, and at the time of this report, the disease had not recurred.

\section{Discussion}

Desmoid tumor is a very rare disease, comprising of only $3 \%$ of soft tissue tumors and $<0.03 \%$ of all neoplasms. ${ }^{3,6}$ Although desmoid tumor mainly occurs in the abdominal wall of 25- to 35-year-old parous women, ${ }^{1}$ mostly it occurs in the breasts of women aged between 13 and 80 years.
However, some studies report that it also occurs in men., ${ }^{411}$ The most common extra-abdominal lesions are found in the shoulder girdle, pelvis, and thigh. ${ }^{8,12}$ The etiology of the disease remains unknown. Most of them occur sporadically; ${ }^{5}$ however, intra-abdominal desmoid tumors seem to be related to FAP or GS and any germ line mutation. ${ }^{13}$ A prior history of trauma has been reported to be associated with this tumor in one of every four patients ${ }^{14}$ and has also been associated with fibromatosis of the breast and breast augmentation. ${ }^{2,5,12,15,16}$ Fibromatosis of the breast can occur primarily due to breast parenchyma and by secondary invasion from the musculoaponeurotic layer of the pectoral muscle.

Clinically, breast fibromatosis usually presents as a painless mass without a skin lesion, although skin involvement and retractions have been reported as rare presentations. In our report, Case 1, the tumor in the subareolar area, had nipple retraction, representative of skin involvement, and invasion by the tumor.

Desmoid tumors are frequently undetected on conventional radiographs because they seemed to be of soft tissue
A

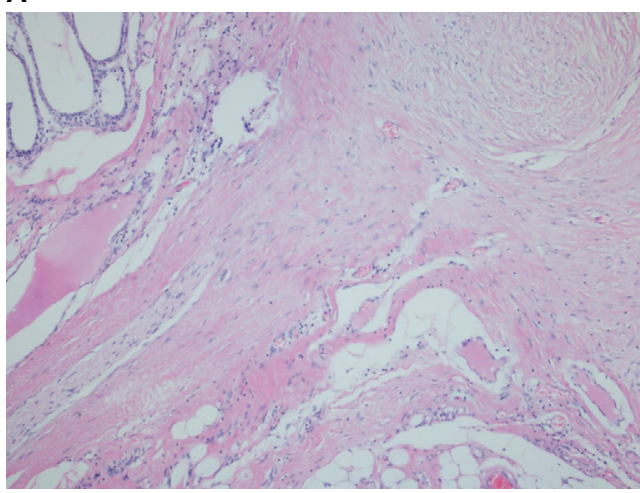

B

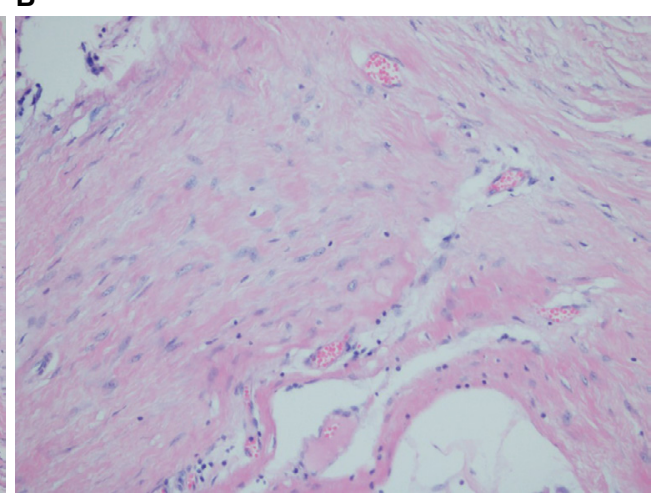

Figure 2 Extra-abdominal desmoid tumor demonstrating infiltrative border $(\mathbf{A})$ with characteristic features of spindle cells among dense collagenous and fibrous stroma (B). Note: $($ A) $\mathrm{H} \& \mathrm{E} \times 40 ;(\mathbf{B}) \mathrm{H} \& \mathrm{E} \times 200$.

Abbreviation: H\&E, hematoxylin and eosin.

A

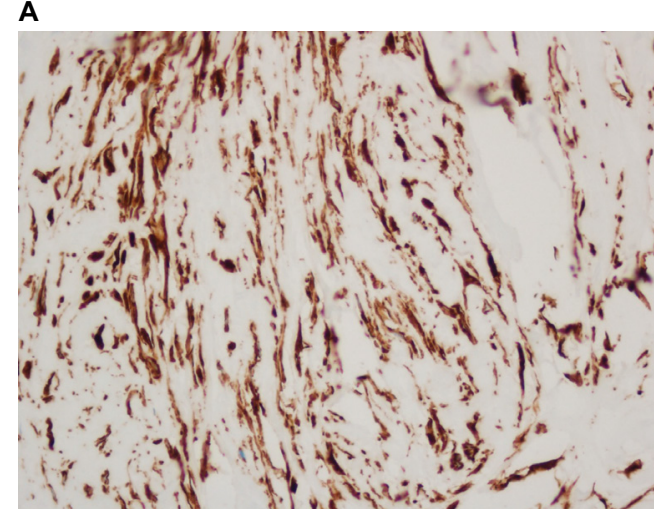

B

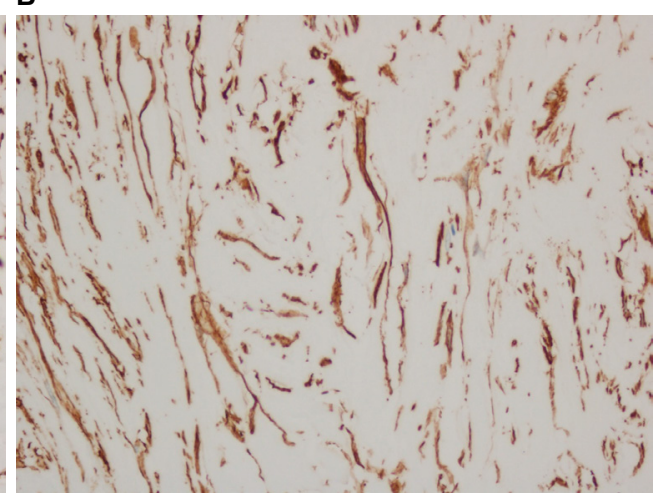

Figure 3 Immunohistochemistry demonstrating positive vimentin (A) and actin (B). Note: Magnification: $\times 100$. 
A

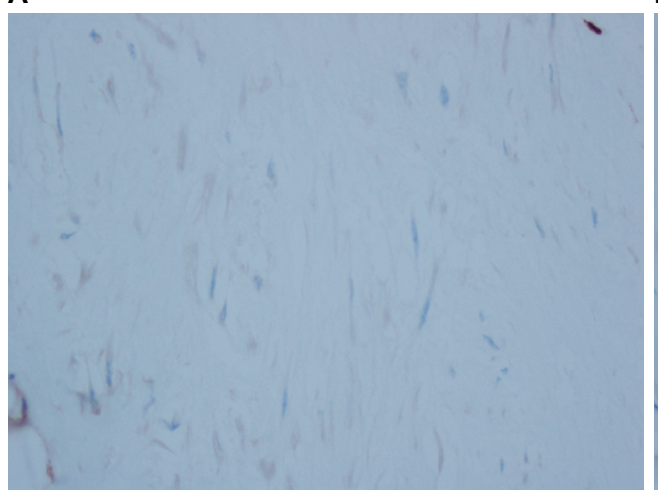

B

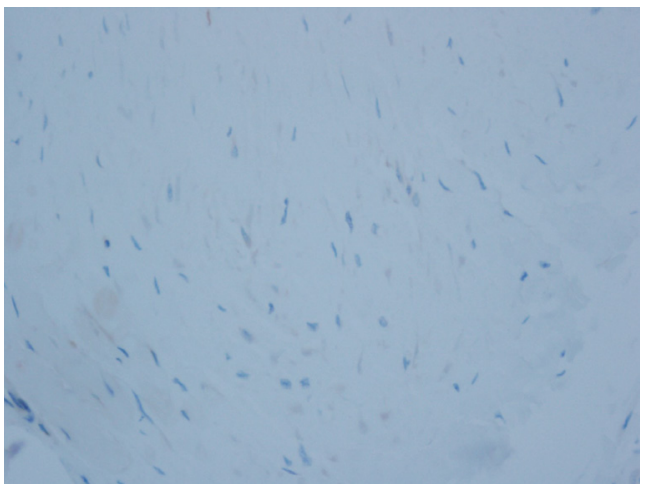

Figure 4 Immunohistochemistry demonstrating negative CD34 (A) and desmin (B). Note: Magnification: $\times 100$.

density or an amorphous mass. Typical mammograms of these lesions show spiculated masses that cannot exclude breast carcinoma. ${ }^{2}, 17 \mathrm{~A}$ common ultrasound finding is an irregularly shaped hypoechoic mass. Similar to the literature, the imaging in our report could not exclude breast cancer.

In gross pathology, a desmoid tumor can be described as a well-circumscribed, nodular, irregular, or infiltrative lesion and white in color, with firm consistency. The cut-surface usually shows an nonencapsulated mass with fibrous, gray and white nodular parenchyma. ${ }^{18}$ In microscopic pathology, the important feature for diagnosis is the presence of bland-looking spindle cells arranged in long sweeping and intersecting fascicles ${ }^{11,14}$ or collagenous stroma. By immunohistochemistry, the positive presence of actin and vimentin is useful for the diagnosis of desmoid tumor. Desmin is rarely positive, whereas $\mathrm{S} 100$ and CD34 are usually negative; $\beta$-catenin nuclear staining is an option for diagnosis, which may be only focally positive. ${ }^{1}$ Few studies have shown that many sporadic fibromatosis cases have CTNNB1 mutation. ${ }^{19,20}$ In our report, both the cases revealed a nonencapsulated mass with a characteristic of spindle cells among dense collagenous stroma. The immunohistochemistry showed positive vimentin and actin with negative desmin and CD34 in both the cases. Nevertheless, $\beta$-catenin nuclear staining and CTNNB1 mutation cannot be done at our institution due to many limitations, but it challenges our ability to try in the future.

Management remains controversial because of the limited data due to its low incidence. During the last 10 years, the treatment of choice is surgical excision with clear margins, ${ }^{21,22}$ since these are locally aggressive diseases, as was performed in both of our cases. The positive margin seems to be associated with recurrent disease, ${ }^{23,24}$ but not all positive margins were recurrent. ${ }^{7,25}$ The complete excision could be avoided in a selected patient because the operation to achieve a clear margin may have negative cosmetic and functional outcomes, such as a superficial lesion and subareolar lesion, that may require nipple areolar complex removal. Recurrent disease has been observed in negative margins, but Bonvalot et al proposed the algorithm of a more conservative wait-and-see approach in a less critical site with an asymptomatic lesion. ${ }^{26}$ If the lesion progresses by RECIST (response evaluation criteria in solid tumor) criteria, then treatment is needed. Systemic therapy, such as antihormone therapy, vinca alkaloid-doxorubicin, and tyrosine kinase inhibitor, has a role in the progress of the disease, and magnetic resonance imaging is used for evaluation. If the lesion still increases in size, surgery is recommended for those patients when resection is feasible without major sequelae. For head-and-neck cancer patients, radiation therapy is recommended. Recurrence following surgery ranges between $18 \%$ and $29 \%$ within the first 2 years. ${ }^{1}$

Along with the bilateral desmoid tumor being extremely rare, there is another very rare disease of the breast reported, which is myofibroblastoma of the breast. The myofibroblastoma of the breast is a rare benign mesenchymal lesion that is similar to solitary fibrous tumor, benign fibrous histiocytoma. Mostly, it occurs in woman and old men. Patients usually present with a palpable, well-defined solid mass. Its findings vary in mammogram and ultrasound imaging and may look like a hamartoma or fibroadenoma. This lesion is classified as a benign spindle cell tumor that should be investigated to find the definite diagnosis of fibroadenoma or not, but this tumor is negative in $\mathrm{S} 100$ and positive for CD34, actin, and vimentin. ${ }^{27,28}$

\section{Conclusion}

Desmoid tumor of the breast is rare, and bilateral lesions are extremely rare. They are indistinguishable from breast carcinoma by mammogram and ultrasound. Triple assessment should be completed for a definitive diagnosis to give the best management. 


\section{Disclosure}

The authors report no conflicts of interest in this work.

\section{References}

1. Taylor TV, Sosa J. Bilateral breast fibromatosis: case report and review of the literature. J Surg Edu. 2011;68(4):320-325.

2. Neuman HB, Brogi E, Ebrahim A, Brennan MF, Van Zee KJ. Desmoid tumors (fibromatoses) of the breast: a 25-year experience. Ann Surg Oncol. 2008;15(1):274-280.

3. Greenberg D, McIntyre H, Ramsaroop R, Arthur J, Harman J. Aggressive fibromatosis of the breast: a case report and literature review. Breast J. 2002;8(1):55-57.

4. Smarrito S, Salmon R. [Desmoid tumor in a male breast in the context of Gardner's syndrome. Case report]. Ann Chir. 2005;130(1):40-43. French.

5. Chummun S, McLean NR, Abraham S, Youseff M. Desmoid tumour of the breast. J Plast Reconstr Aesthet Surg. 2010;63(2):339-345.

6. Garg P, Chufal SS, Gupta N, Pant P, Thapliyal NC. Multicentric aggressive mammary fibromatosis with cytological features and review of literature. J Clin Diagn Res. 2014;8(5):FD01-FD03.

7. Rosen PP, Ernsberger D. Mammary fibromatosis. A benign spindle-cell tumor with significant risk for local recurrence. Cancer. 1989;63(7): 1363-1369.

8. Brown CS, Jeffrey B, Korentager R, Hughes K. Desmoid tumors of the bilateral breasts in a patient without Gardner syndrome: a case report and review of literature. Ann Plast Surg. 2012;69(2):220-222.

9. Al-Khyatt W, Goyal A, Mansel RE. Nipple-sparing skin-sparing mastectomy and vertical latissimus dorsi flap reconstruction for bilateral fibromatosis of the breast. Clin Breast Cancer. 2010;10(1):E1-E2.

10. Papantoniou V, Koutsikos J, Sotiropoulou M, Feida E, Tsiouris S. Recurrent bilateral mammary fibromatosis (desmoid tumor) imaged with technetium-99m pentavalent dimercaptosuccinic acid [99mTc-(V) DMSA] scintimammography. Gynecol Oncol. 2005;97(3):964-969.

11. Erguvan-Dogan B, Dempsey PJ, Ayyar G, Gilcrease MZ. Primary desmoid tumor (extraabdominal fibromatosis) of the breast. AJR: Am J Roentgenol. 2005;185(2):488-489.

12. Schiller VL, Arndt RD, Brenner RJ. Aggressive fibromatosis of the chest associated with a silicone breast implant. Chest. 1995;108(5):1466-1468.

13. Wong SL. Diagnosis and management of desmoid tumors and fibrosarcoma. J Surg Oncol. 2008;97(6):554-558.
14. Lopez R, Kemalyan N, Moseley HS, Dennis D, Vetto RM. Problems in diagnosis and management of desmoid tumors. Am J Surg. 1990;159(5): $450-453$.

15. Shim HS, Kim SJ, Kim OH, Jung HK, Kim SJ, Kim W, Kim WW. Fibromatosis associated with silicone breast implant: ultrasonography and MR imaging findings. Breast J. 2014;20(6):645-649.

16. Seo YN, Park YM, Yoon HK, Lee SJ, Choo HJ, Ryu JH. Breast fibromatosis associated with breast implants. Jpn J Radiol. 2015;33(9):591-597.

17. Lee SM, Lee JY, Lee BH, Kim SY, Joo M, Kim JI. Fibromatosis of the breast mimicking an abscess: case report of unusual sonographic features. Clin Imaging. 2015;39(4):685-688.

18. Dwyer JB, Clark BZ. Low-grade fibromatosis-like spindle cell carcinoma of the breast. Arch Pathol Lab Med. 2015;139(4):552-557.

19. Aitken SJ, Presneau N, Kalimuthu S, et al. Next-generation sequencing is highly sensitive for the detection of beta-catenin mutations in desmoid-type fibromatoses. Virchows Archi. 2015;467(2):203-210.

20. Huss S, Nehles J, Binot E, et al. $\beta$-catenin (CTNNB1) mutations and clinicopathological features of mesenteric desmoid-type fibromatosis. Histopathology. 2013;62(2):294-304.

21. Shen C, Zhou Y, Che G. Management of a female with recurrence of fibromatosis of the chest wall adjacent to the breast: a case report. J Cardiothorac Surg. 2013;8:41.

22. Horevoets J, Smet B, Pattyn P, van Dorpe J, Vuylsteke P. Desmoid tumour of the breast: case report and review of the literature. Acta Chir Belg. 2013; 113(4):304-307.

23. Povoski SP, Marsh WL, Spigos DG, Abbas AE, Buchele BA. Management of a patient with multiple recurrences of fibromatosis (desmoid tumor) of the breast involving the chest wall musculature. World J Surg Oncol. 2006;4:32.

24. Wargotz ES, Norris HJ, Austin RM, Enzinger FM. Fibromatosis of the breast. A clinical and pathological study of 28 cases. Am J Surg Pathol. 1987;11(1):38-45.

25. Gump FE, Sternschein MJ, Wolff M. Fibromatosis of the breast. Surg Gynocol Oncol. 1981;153(1):57-60.

26. Bonvalot S, Desai A, Coppola S, Le Péchoux C, Terrier P, Dômont J, Le Cesne A. The treatment of desmoid tumors: a stepwise clinical approach. Annals of Oncology. 2012;23(suppl 10):x158-x166.

27. Mele M, Jensen V, Wronecki A, Lelkaitis G. Myofibroblastoma of the breast: case report and literature review. Int J Surg Case Rep. 2011;2(6): 93-96.

28. Magro G. Mammary myofibroblastoma: a tumor with a wide morphologic spectrum. Arch Pathol Lab Med. 2008;132(11):1813-1820.
International Medical Case Reports Journal

\section{Publish your work in this journal}

The International Medical Case Reports Journal is an international, peer-reviewed open-access journal publishing original case reports from all medical specialties. Previously unpublished medical posters are also accepted relating to any area of clinical or preclinical science. Submissions should not normally exceed 2,000 words or
Submit your manuscript here: https://www.dovepress.com/international-medical-case-reports-journal-jourat

4 published pages including figures, diagrams and references. The manuscript management system is completely online and includes a very quick and fair peer-review system, which is all easy to use. Visit http://www.dovepress.com/testimonials.php to read real quotes from published authors. 